\title{
Associations between postnatal weight gain, change in postnatal pulmonary function, formula feeding and early asthma
}

\author{
S Turner, G Zhang, S Young, M Cox, J Goldblatt, L Landau, P Le Souëf
}

School of Paediatrics and Child Health, University of Western Australia and Department of Respiratory Medicine, Princess Margaret Hospital for Children, Perth, Australia

Correspondence to: Dr S Turner, Department of Child Health, Royal Aberdeen Children's Hospital, Foresterhill, Aberdeen AB25 2ZD, UK; s.w.turner@abdn.ac.uk

Received 7 August 2006 Accepted 10 September 2007 Published Online First 28 September 2007

\section{ABSTRACT \\ Background: A study was undertaken to examine factors that might influence lung function during infancy and to test the hypothesis that change in weight during infancy is negatively associated with change in lung function.}

Methods: Weight, length and maximal flow at functional residual capacity ( $\mathrm{V}^{\prime}$ maxFRC) were measured at ages 1 and 12 months. V'maxFRC was adjusted for length. Asthma symptoms and age at introduction of formula feeds were identified from questionnaires. Groups were dichotomised by $V^{\prime}$ maxFRC at 1 month and change in $V^{\prime} \operatorname{maxFRC}$.

Results: 154 infants were assessed at ages 1 and 12 months. The change in V'maxFRC was inversely associated with change in weight $\left(r=-0.18, r^{2}=0.13\right.$, $p<0.001)$. The group with lower $V^{\prime} \max F R C$ at 1 month and reduced change in V'maxFRC over infancy had the greatest weight gain $(p=0.003)$ and increased risk for asthma symptoms by 3 years ( $p=0.017$ ) but not afterwards. Exclusive breast feeding to 6 months was associated with a mean reduction in weight gain at age 12 months in comparison with earlier introduction of formula milk (mean difference $0.65 \mathrm{~kg}, \mathrm{p}=0.001$ ), and was also associated with reduced asthma symptoms at 3 years (odds ratio $0.44, p=0.043$ ) but not at 6 or 11 years of age.

Conclusions: Weight gain in infancy is inversely associated with change in lung function during infancy. Postnatal weight gain may be indirectly associated with early transient asthma symptoms via an influence on lung growth during infancy, and this is potentially modifiable by breast feeding. These associations could be relevant to the clinically recognised syndrome of the "fat happy wheezer"

Wheezing is a common symptom in early life, affecting up to one-third of young children..$^{1-3}$ There are several factors associated with early wheeze including abnormalities of pulmonary function. ${ }^{14-6}$ Wheezy infants have obstructed pulmonary function ${ }^{145}$ and increased airway

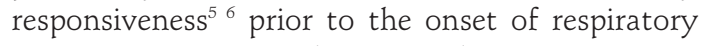
symptoms. Factors that may be important to abnormal pulmonary function in early life include male gender, ${ }^{7}$ a family history of asthma, ${ }^{8}$ maternal smoking during pregnancy ${ }^{9}$ and low birth weight. ${ }^{10}$

In a recent publication, Lucas et $a l^{11}$ showed that lung function (maximal flow at functional residual capacity, V'maxFRC) in young infants was negatively associated with postnatal weight gain, independent of length and birth weight. A negative relationship between weight and infant lung function has also been reported in a population of infants born prematurely. ${ }^{12}$ One suggestion ${ }^{11}$ is that these associations may be due to "catch up" in somatic growth in infants of low birth weight after a period of in utero stress, and that the postnatal somatic growth exceeded growth in pulmonary function. An alternative mechanism could be that some babies of normal birth weight experience rapid postnatal weight gain due to an excessively calorie-rich diet, and growth in pulmonary function is either impaired due to less favourable airway wall or airspace growth or is unable to match somatic growth.

In the present study we sought to determine whether the change in V'maxFRC between ages 1 and 12 months was negatively influenced by the change in weight over infancy. Our secondary aim was to relate change in $V^{\prime}$ maxFRC to infant feeding practices and the development of asthma symptoms. The data were taken from a longitudinal cohort study (Perth Infant Asthma Follow-Up Study) where serial measures of pulmonary function were taken during infancy, a contemporaneous record of infant feeding was made and a detailed follow-up was completed at 11 years of age. ${ }^{4}$

\section{METHODS}

\section{Subjects and study protocol}

Study participants were recruited from expectant parents attending a local antenatal clinic. The details of recruitment have been described previously. ${ }^{13}$ There was no selection for parental asthma or atopy and exclusion criteria included delivery before 36 weeks gestation and the presence of respiratory symptoms in the first month of life. A history of maternal or paternal smoking during the pregnancy and of asthma (ever) was recorded at enrolment. At ages 1, 6 and 12 months, weight, length and pulmonary function were measured, skin prick reactivity to common allergens was determined and urinary cotinine levels were measured. During infancy, mothers returned monthly postal questionnaires that reported details of feeding and respiratory symptoms. Annual postal questionnaires were returned between ages 2 and 6 years which detailed the presence of respiratory symptoms. At 11 years of age the children completed an assessment which included a respiratory questionnaire, spirometry, inhaled histamine challenge and skin prick reactivity to common allergens.

The Institutional Ethics Committee of Princess Margaret Hospital approved this study. Written 
consent was obtained from parents and verbal assent was obtained from the children.

\section{Classification of respiratory symptoms}

Current doctor diagnosed asthma (DDA) at all ages was defined as an affirmative response to the question: "Does your child have asthma which has been diagnosed by a doctor?" Doctor diagnosed asthma by 3 years of age was defined as the presence of DDA at either 2 or 3 years of age, DDA between 4 and 6 years was defined as the presence of DDA at 4, 5 or 6 years of age.

\section{Infant pulmonary function}

The techniques used have been described in detail elsewhere. ${ }^{13}$ After induction of sleep with chloral hydrate, a tightly fitting non-distensible jacket was applied to the chest. A balloon within the jacket was rapidly inflated at the end of tidal inspiration and V'maxFRC was derived from the resultant partial forced expiratory manoeuvre. The mean of at least five technically acceptable manoeuvres was reported.

\section{Urinary cotinine analysis}

Urine collection bags were placed by the parents a few hours prior to attending the hospital. Urine samples were stored for a maximum of 5 days at $4^{\circ} \mathrm{C}$ until transfer to a freezer at $-20^{\circ} \mathrm{C}$. The urine was analysed later in batches. Cotinine was measured by radioimmunoassay, standardised to creatinine concentration to adjust for urine dilution and expressed in units of $\mathrm{ng} / \mathrm{mg}$ creatinine. The distribution of urinary cotinine was skewed with a long right-hand tail and was log transformed prior to analysis to achieve a near normal distribution

\section{Skin prick testing}

Skin reactivity of infants to cows' milk, egg white, rye grass and Dermatophagoides farinae was determined using the skin prick test as described by Pepys. ${ }^{14}$ For the assessment at 11 years, skin reactivity to the following additional six allergens was also assessed: mixed grass (no 7); Dermatophagoides pteronyssinus; cat dander; dog dander; Alternaria alternans; and Aspergillus fumigatus. All allergens were supplied by Hollister-Stier, Elkhart, Indiana, USA. Histamine sulphate $(10 \mathrm{mg} / \mathrm{ml})$ was used as the positive control and $0.9 \%$ saline as the negative control. A positive skin test was defined as a weal to any allergen $\geqslant 3 \mathrm{~mm}$ in its longest dimension or $\geqslant 3 \mathrm{~mm}$ greater than the negative control.

\section{Childhood pulmonary function}

A portable spirometer (Pneumocheck Spirometer 6100; WelchAllyn, Skaneateles Falls, New York, USA) was used in accordance with published guidelines. ${ }^{15}$ The rapid inhalation technique $^{16}$ was used to determine bronchial hyperresponsiveness (BHR) to histamine; BHR was defined as a fall of at least $20 \%$ in forced expiratory volume in $1 \mathrm{~s}\left(\mathrm{FEV}_{1}\right)$ after inhalation of a dose of $\leqslant 7.8 \mu \mathrm{mol}$ histamine. Short-acting bronchodilators were withheld for at least $6 \mathrm{~h}$ and long-acting $\beta$ agonists were withheld for $12 \mathrm{~h}$ before testing; no children were treated with leucotriene antagonists.

\section{Statistical analysis}

V'maxFRC was log transformed prior to linear regression analysis to achieve a near normal distribution and divided by length (in centimetres) to adjust for length. A Student $t$ test (two-tailed, equivariance assumed), $\chi^{2}$ analysis or analysis of variance were used as appropriate to compare differences between groups. The primary outcome variable (which was normally distributed) was the percentage change in lengthadjusted V'maxFRC which was calculated as follows:

\section{(log V'maxFRC at 12 months)/length at 12 months) $\times 100$ (log V'maxFRC at 1 month)/length at 1 month}

The primary explanatory variable was percentage change in weight (weight at age 12 months/weight at age 1 month $\times 100$ ). A multiple linear regression model was constructed to adjust for potential confounding variables (including birth weight, $V^{\prime}$ maxFRC at 1 month, exclusive breast feeding for $\geqslant 6$ months and gender). In a forward stepwise manner, these variables were introduced into the model and were retained if they changed the $r^{2}$ value of the model by $>30 \%$; change in weight was the first variable entered. Logistic regression models were created to adjust the relationship between asthma and predictive variables for confounders which were introduced in a forward stepwise manner and only retained in the model if they were significant. A standard statistical program was used for the analyses (SPSS V.13.0) and significance was assumed at 5\%.

\section{RESULTS}

\section{Study subjects}

The study population included 253 individuals (142 boys) in whom V'maxFRC was measured in 243 at the age of 1 month, 194 at the age of 6 months and 165 at the age of 12 months. Paired measurements of V'maxFRC were available in 154 infants at 1 and 12 months of age, in whom the presence or absence of DDA between ages 2 and 3 years was known in 145, the presence or absence of DDA between ages 4 and 6 years was known in 136 and duration of breast feeding for $\geqslant 6$ months was established in 127. Paired measurements of V'maxFRC were also available in 182 infants at 1 and 6 months of age and in 159 infants at 6 and 12 months of age. The 53 infants lost to follow-up after 1 month of age did not differ from the remaining cohort (table 1$)$.

\section{Lung function, weight, feeding practices, urinary cotinine and atopy during infancy}

The median (interquartile range, IOR) values for $\mathrm{V}^{\prime} \max F \mathrm{RC}$ at 1,6 and 12 months of age were $93(64,124), 150(120,196)$ and $188(139,277) \mathrm{ml} / \mathrm{s}$, respectively. The mean (SD) change in length-adjusted V'maxFRC between 1 and 12 months of age was 87 (15)\%; the corresponding change between 1 and 6 months was $92(13) \%$ and between 6 and 12 months was $94(13) \%$. V'maxFRC/length was reduced in boys compared with girls at each assessment and this difference was significant at 1 month of age $(p=0.017)$. The mean (SD) weight at each assessment was as follows: $4.9(0.7) \mathrm{kg}$ at 1 month, $8.3(1.0) \mathrm{kg}$ at 6 months and 10.4 (1.2) $\mathrm{kg}$ at 12 months of age. The mean (SD) percentage change in weight was $215(30) \%$ between 1 and 12 months, 173 (24)\% between 1 and 6 months and $128(12) \%$ between 6 and 12 months. Boys were heavier on each assessment but the percentage change in weight between assessments did not differ between boys and girls. Seventy infants received only breast milk for the first 6 months and 90 received formula milk within the first 6 months of life. Solids were introduced before 4 months of age in 87 and after this age in 101 infants. The median (IOR) urinary cotinine levels were $101(51,352) \mathrm{ng} / \mathrm{mg}$ creatinine at 1 month $(\mathrm{n}=104), 60$ (25, $303)$ at 6 months $(n=82)$ and $48(26,98)$ at 12 months 
Table 1 Characteristics of infants for whom V'maxFRC was only available at 1 month of age compared with those for whom V'maxFRC was available at 1 month of age and at least a second occasion

\begin{tabular}{|c|c|c|}
\hline & $\begin{array}{l}V^{\prime} \text { maxFRC measured } \\
\text { only at } 1 \text { month of age } \\
(\mathrm{n}=53)\end{array}$ & $\begin{array}{l}V^{\prime} \text { maxFRC measured } \\
\text { at } 1 \text { month of age and } \\
\text { on a second occasion } \\
(n=190)\end{array}$ \\
\hline Male & $56 \%(29 / 53)$ & $56 \%(107 / 190)$ \\
\hline Mother smoked during pregnancy & $27 \%(14 / 52)$ & $23 \%(43 / 190)$ \\
\hline $\begin{array}{l}\text { At least one parent with a history } \\
\text { of asthma }\end{array}$ & $26 \%(12 / 47)$ & $33 \%(61 / 185)$ \\
\hline Mean (SD) birth weight $(\mathrm{kg})$ & $3.4(0.5)$ & $3.4(0.5)$ \\
\hline $\begin{array}{l}\text { Median (IQR) V'maxFRC at age } \\
1 \text { month }(\mathrm{ml} / \mathrm{s})\end{array}$ & $88(60,119)$ & $94(66,130)$ \\
\hline $\begin{array}{l}\text { Mean (SD) length at } 1 \text { month } \\
\text { assessment }(\mathrm{cm})\end{array}$ & $56(5)$ & $55(3)$ \\
\hline $\begin{array}{l}\text { Formula feeds introduced by } \\
1 \text { month of age }\end{array}$ & $32 \%(17 / 53)$ & $27 \%(34 / 124)$ \\
\hline
\end{tabular}

$(\mathrm{n}=72)$. Thirty-two individuals had at least one positive skin prick test during infancy.

\section{Percentage change in weight and percentage change in V'maxFRC}

There was a negative relationship between percentage change in $V^{\prime}$ maxFRC and percentage change in weight between ages 1 and 12 months $\left(r=-0.18, r^{2}=0.13, p<0.001\right.$, fig 1$)$; this relationship was consistent over the first and second 6 months of infancy $\left(r=-0.18, r^{2}=0.11, p=0.001\right.$ and $r=-0.34$, $r^{2}=0.15, p<0.001$, respectively). The relationship between the change in $V^{\prime}$ maxFRC and weight between 1 and 12 months remained significant when confounders were considered: $r=-0.14$ when $V^{\prime}$ maxFRC at 1 month was considered; $r=-0.18$ when gender, birth weight urinary cotinine at 1 month or atopy was considered; and $r=-0.20$ when breast feeding was considered. When individuals were dichotomised by weight gain and $V^{\prime}$ maxFRC/length at 1 month, the greatest percentage change in $V^{\prime}$ maxFRC between 1 and 12 months of age was in those with a lower $V^{\prime}$ maxFRC at 1 month and a lower weight gain between ages 1 and 12 months (mean change $99 \%$; fig 2). The remaining mean percentage changes in V'maxFRC were as follows: $88 \%$ for low V'maxFRC and high weight gain; 81\% for high V'maxFRC and low weight gain; $77 \%$ for high $V^{\prime}$ maxFRC and high weight gain $(p<0.001$ for trend, ANOVA).

\section{Weight gain, infant lung function and asthma}

Asthma symptoms were not associated with the percentage change in V'maxFRC per se or the percentage change in weight between ages 1 and 12 months. The proportion with DDA by 3 years of age was highest (38\%) in individuals with a low $V^{\prime} \operatorname{maxFRC}$ at 1 month and a smaller change in $V^{\prime}$ maxFRC between 1 and 12 months and lowest (13\%) in those with a high V'maxFRC at 1 month and a greater change in V'maxFRC ( $p=0.017$ for trend adjusting for percentage change in weight, table 2).

\section{Weight gain, infant feeding and asthma}

Infants in whom formula milk was introduced by 6 months of age were no heavier at birth or 1 month than those breast fed to at least 6 months but they had greater weight gain between 1

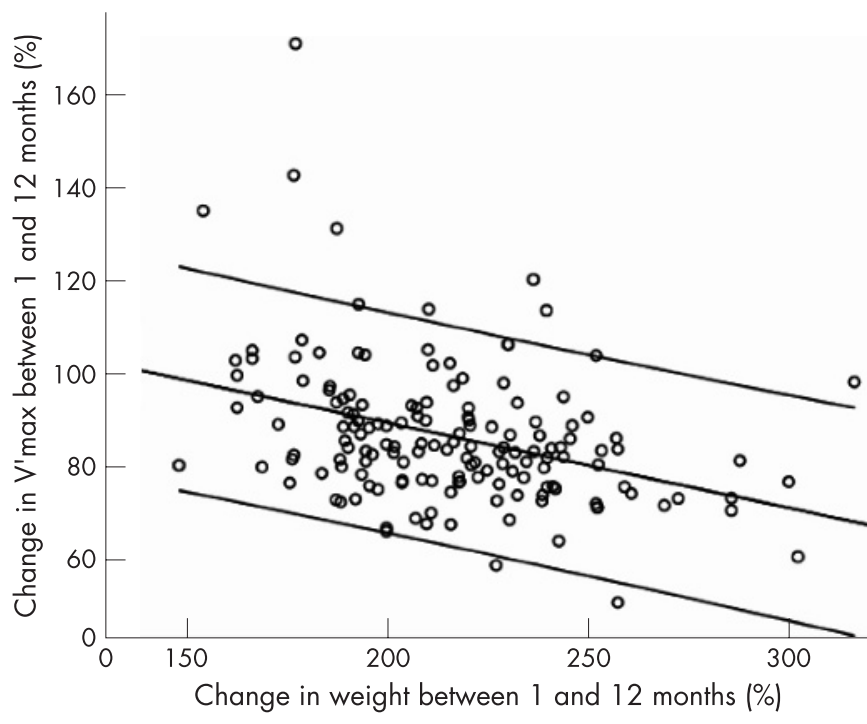

Figure 1 Scatterplot comparing change in weight and change in lengthadjusted maximal flow at functional residual capacity (V'maxFRC) between 1 and 12 months of age. The lines correspond to the mean regression line and its $95 \%$ confidence intervals $\left(r^{2}=0.13, p<0.001\right.$, $\mathrm{n}=154)$.

and 12 months (mean increase $0.65 \mathrm{~kg}$ (95\% confidence interval (CI) 0.27 to 1.04$), p=0.001)$ and increased weight at 6 months (mean increase $0.34 \mathrm{~kg}(95 \%$ CI 0.02 to 0.70$), p=0.036)$ and 12 months of age (mean increase $0.65 \mathrm{~kg}$ (95\% CI 0.25 to 1.05), $p=0.002)$. Diagnosed asthma by 3 years was reduced in association with exclusive breast feeding until at least 6 months

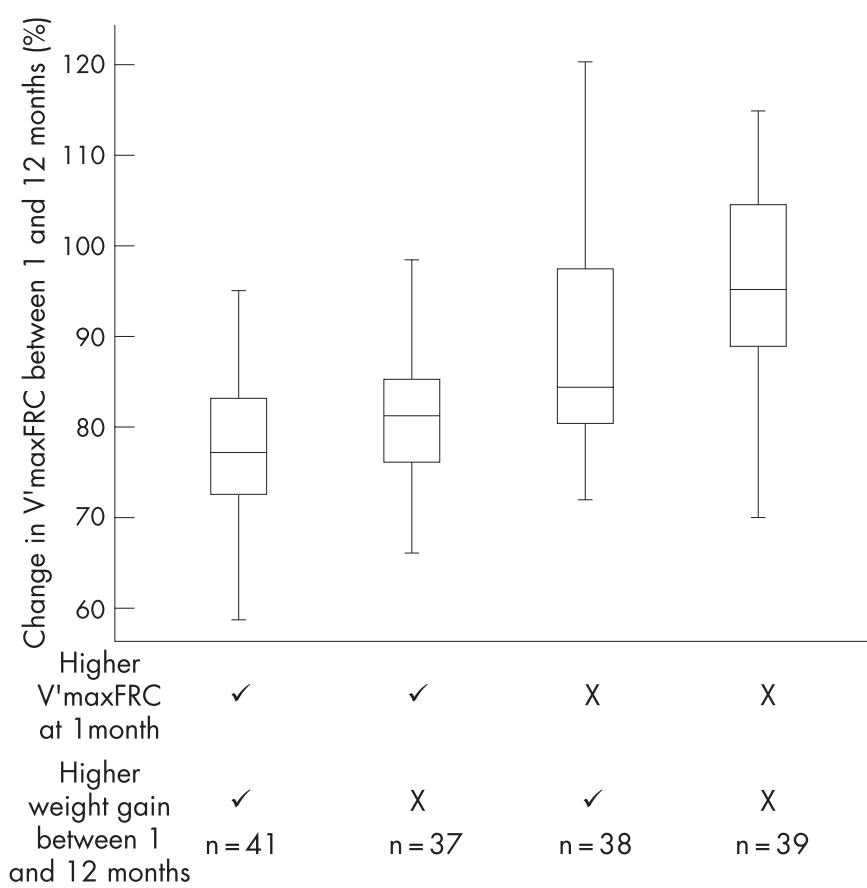

Figure 2 Box and whisker plot comparing the percentage change in length-adjusted maximal flow at functional residual capacity (V'maxFRC) between ages 1 and 12 months between groups categorised by lengthadjusted V'maxFRC at 1 month and weight gain between ages 1 and 12 months. "Higher" values correspond to those greater than the median value. $p<0.001$ trend across groups (analysis of variance with Bonferroni adjustment). 
Table 2 Comparison of characteristics of groups of children defined by V'maxFRC at 1 month of age (dichotomised about the median value into high or low) and percentage change in V'maxFRC between 1 and 12 months of age (dichotomised about the median value into high and low)

\begin{tabular}{|c|c|c|c|c|c|}
\hline & $\begin{array}{l}\text { Low } V^{\prime} \text { maxFRC at } 1 \text { month } \\
\text { and low } V^{\prime} \text { max growth } \\
(\mathrm{n}=21)\end{array}$ & $\begin{array}{l}\text { High V'maxFRC at } 1 \text { month } \\
\text { and low } V^{\prime} \text { max growth } \\
(n=56)\end{array}$ & $\begin{array}{l}\text { Low V'maxFRC at } 1 \text { month } \\
\text { and high V'max growth } \\
(\mathrm{n}=56)\end{array}$ & $\begin{array}{l}\text { High V'maxFRC at } 1 \text { month } \\
\text { and high } V^{\prime} \text { max growth } \\
(\mathrm{n}=22)\end{array}$ & Trend test \\
\hline $\begin{array}{l}\text { Diagnosed asthma by } \\
3 \text { years of age }\end{array}$ & $38 \%(8 / 21)$ & $29 \%(15 / 52)$ & $32 \%(14 / 52)$ & $13 \%(3 / 24)$ & $\mathrm{p}=0.017^{*}$ \\
\hline $\begin{array}{l}\text { Diagnosed asthma at } \\
4-6 \text { years of age }\end{array}$ & $33 \%(6 / 18)$ & $20 \%(10 / 50)$ & $33 \%(16 / 49)$ & $11 \%(2 / 19)$ & $p=0.149 *$ \\
\hline $\begin{array}{l}\text { Diagnosed asthma at } \\
11 \text { years }\end{array}$ & $20 \%(4 / 20)$ & $13 \%(6 / 46)$ & $16 \%(7 / 45)$ & $5 \%(1 / 20)$ & $p=0.456^{*}$ \\
\hline $\begin{array}{l}\text { Mean (SD) \% change in } \\
\text { weight between } 1 \text { and } \\
12 \text { months }\end{array}$ & $230(28)$ & $222(32)$ & $206(29)$ & $210(24)$ & $p=0.003$ \\
\hline Mean (SD) birth weight $(\mathrm{kg})$ & $3.2(0.5)$ & $3.6(0.4)$ & $3.5(0.5)$ & $3.4(0.5)$ & $p=0.039$ \\
\hline $\begin{array}{l}\text { Exclusive breast feeding for } \\
\text { at least } 6 \text { months }\end{array}$ & $24 \%(4 / 17)$ & $37 \%(18 / 49)$ & $44 \%(18 / 41)$ & $31 \%(5 / 16)$ & $p=0.495$ \\
\hline Male (number) & $67 \%(14)$ & $54 \%(30)$ & $63 \%(35)$ & $41 \%(9)$ & $p=0.253$ \\
\hline $\begin{array}{l}\text { Maternal smoking during } \\
\text { pregnancy }\end{array}$ & $19 \%(4 / 21)$ & $13 \%(7 / 56)$ & $23 \%(13 / 56)$ & $23 \%(5 / 22)$ & $p=0.493$ \\
\hline Parental asthma & $35 \%(7 / 20)$ & $35 \%(19 / 55)$ & $33 \%(18 / 55)$ & $23 \%(5 / 22)$ & $p=0.772$ \\
\hline
\end{tabular}

V'maxFRC, maximal flow at functional residual capacity.

${ }^{*}$ Adjusted for percentage weight gain between 1 and 12 months.

of age (odds ratio (OR) 0.44 (95\% CI 0.19 to 1.00), $p=0.043$ ), independent of gender, maternal asthma and maternal smoking during pregnancy and weight gain between 1 and 12 months; this relationship did not persist for asthma during the second 3 years (OR 0.80 (95\% CI 0.37 to 1.70$)$ ) or at 11 years of age (OR 0.92 (95\% CI 0.37 to 1.70$)$ ). The percentage change in $V^{\prime}$ maxFRC between 1 and 12 months of age was not associated with duration of exclusive breast feeding. The introduction of solids before or after 4 months of age was not associated with change in weight and V'maxFRC or asthma.

\section{Relationship between factors measured in infancy and outcomes at $\mathbf{1 1}$ years of age}

Of the 154 individuals in whom V'maxFRC was determined at 1 and 12 months of age, 127 had a detailed assessment at 11 years of age. Mid expiratory flow $\left(\mathrm{FEF}_{25-75}\right)$ at 11 years of age was independently and positively associated with the percentage change in $V^{\prime}$ maxFRC; this was also independent of birth weight, $V^{\prime}$ maxFRC/length at 1 month, breast feeding and atopy and BHR at 11 years (table 3 ). Eighteen children assessed at 11 years of age (14\%) had current DDA, 65 (51\%) were atopic

Table 3 Regression coefficients, confidence intervals and $p$ values from multivariate regression model in which $\mathrm{FEF}_{25-75}$ at 11 years of age was the outcome variable

\begin{tabular}{|c|c|c|}
\hline & $\begin{array}{l}\text { Regression coefficient } \\
(95 \% \mathrm{Cl})\end{array}$ & p Value \\
\hline Height at age 11 years & 3.266 (2.124 to 4.409$)$ & $<0.001$ \\
\hline $\begin{array}{l}\mathrm{PD}_{20}<7.8 \mu \mathrm{g} \text { histamine at } \\
\text { age } 11 \text { years }\end{array}$ & $-0.246(-0.439$ to -0.053$)$ & 0.013 \\
\hline $\begin{array}{l}\text { Log V'maxFRC/length at } \\
1 \text { month }\end{array}$ & $1.127(0.496$ to 1.758$)$ & 0.001 \\
\hline $\begin{array}{l}\% \text { change in } V^{\prime} \text { maxFRC } \\
\text { between } 1 \text { and } 12 \text { months }\end{array}$ & $0.012(0.001$ to 0.024$)$ & 0.039 \\
\hline $\begin{array}{l}\% \text { change in weight between } \\
1 \text { and } 12 \text { months }\end{array}$ & $0.003(0.000$ to 0.006$)$ & 0.068 \\
\hline
\end{tabular}

$\mathrm{FEF}_{25-75}$, mid expiratory flow; $\mathrm{PD}_{20}$, dose of histamine provoking a fall in forced expiratory volume in $1 \mathrm{~s}$ of $\geqslant 20 \%$; V'maxFRC, maximal flow at functional residual capacity;

Data from 121 individuals are included. Neither birth weight, exclusive breast feeding to 6 months of age nor atopy at 11 years were related to $\mathrm{FEF}_{25-75}$ and did not remain in the model. There was a significant $(p=0.031)$ and positive interaction term between percentage change in weight and height at 11 years. and $41(32 \%)$ had BHR; none of these was related to the percentage change in $V^{\prime}$ maxFRC or weight, or to the duration of exclusive breast feeding.

\section{DISCUSSION}

This analysis studied the influence of postnatal weight gain on lung function during infancy. Our study has shown potentially important relationships between somatic and pulmonary growth during infancy, infant feeding practices and early transient asthma symptoms, and also pulmonary function in later childhood. Our hypothesis was that weight gain would be negatively related to change in $V^{\prime}$ maxFRC between 1 and 12 months of age and the data supported this. A series of interrelated associations became apparent when exploring the relevance of changes in postnatal weight gain and pulmonary function to respiratory symptoms, and this indicated a rather complex potentially causative mechanism (fig 3). Infants with lower birth weight and greater somatic growth during infancy had relatively reduced growth in lung function which was associated with transient asthma symptoms when combined with reduced lung function at 1 month. Exclusive breast feeding to 6 months had a potentially modifiable effect on excessive

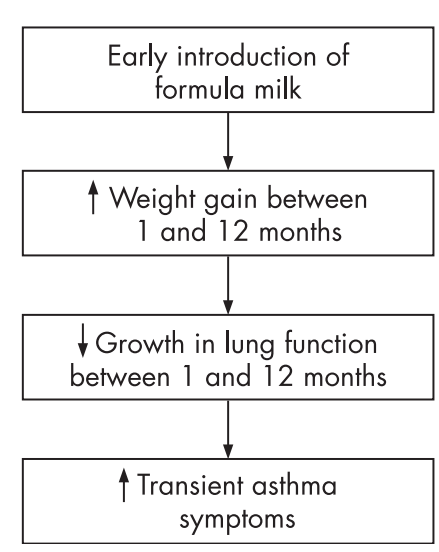

Figure 3 Schematic diagram summarising the associations reported in the present study. Other relevant factors include birth weight and maximal flow at functional residual capacity at 1 month. 
weight gain during infancy and was associated with reduced transient asthma symptoms. These associations could be one explanation for a transient wheezing syndrome in the infant who becomes a "fat happy wheezer".

\section{Relationship between changes in postnatal weight gain and V'maxFRC}

A mechanism by which increased postnatal weight gain is associated with a relative reduction in lung growth-as evidenced by change in V'maxFRC-is not clear. This study has shown that the mechanism is independent of gender, atopy and antenatal and postnatal exposure to products of tobacco smoke. In a previous report based on observations taken from this cohort, we have observed that low V'maxFRC at 1 month of age persists at 12 months in some individuals but not others, and that those individuals in whom low V'maxFRC did persist were more likely to wheeze in the first and second years of life. ${ }^{17}$ A mechanism whereby low V'maxFRC occurs throughout infancy in some individuals but not others has not previously been reported, and the findings of the present study suggest that increased postnatal weight gain, possibly in infants of reduced birth weight, may be one factor associated with relatively low growth in pulmonary function during infancy.

\section{Relationship between lung function in infancy and childhood}

Previous studies, including those based on the present cohort, have reported tracking of pulmonary function from early life into later childhood; ${ }^{18}$ however, in the present study we have shown that the relationship between pulmonary function in very early life ("baseline") and that in later life may be modified. Pulmonary function in very early life is mostly influenced by antenatal factors but, during infancy, the level of "baseline" pulmonary function may be modified by postnatal factors and this may include weight gain; thus, lower weight gain during early life could ameliorate adverse later respiratory outcomes associated with reduced "baseline" pulmonary function. Alternatively, the increased weight gain observed among those with low baseline and percentage change in $V^{\prime}$ maxFRC may be inevitable "catch up" growth after in utero stress, and this may not be modifiable.

\section{Infant feeding practices}

In the present study the introduction of formula feeds by 6 months of age was associated with increased postnatal weight gain and early asthma symptoms, and a similar relationship has previously been described among children from Western Australia. ${ }^{19}{ }^{20}$ In their follow-up of a large birth cohort, Oddy et $a l^{19}{ }^{20}$ report associations between less exclusive breast feeding and increased respiratory symptoms in infancy and at 6 years of age; this group also found that a higher body mass index was a risk factor for asthma at the age of 6 years. In the present study we found no relationship between duration of breast feeding and increased asthma beyond 3 years of age, which may be due to the relatively small numbers studied or the effect being limited to early childhood. The relationship between asthma and duration of breast feeding is complex and there are many inconsistencies between studies; ${ }^{21}$ some find a positive relationship, others no relationship and still others find a negative relationship. ${ }^{21}$ The results of the present study could indicate more than one mechanism associating exclusive breast feeding to 6 months with respiratory outcomes; the first could be via altered postnatal weight gain and involve abnormalities in pulmonary function and the second acting independently of pulmonary function.

\section{Study limitations}

There are issues which could be considered when interpreting our results. First, there is invariably regression to the mean for $V^{\prime}$ maxFRC and weight and this may partly explain the inverse relationship observed for change in $V^{\prime}$ maxFRC and change in weight. Infants where regression to the mean was not present (ie, low baseline and percentage change in $V^{\prime}$ maxFRC or high baseline and percentage change in $V^{\prime} \operatorname{maxFRC}$, table 2) were different in terms of early symptoms, birth weight and postnatal weight gain, and these differences cannot be explained by regression of $V^{\prime}$ maxFRC or weight to the mean. Second, a number of analyses were performed during this study and this increases the chance of false positive results. However, our findings were of sufficient consistency to suggest that multiple testing has not influenced our results. Finally, in the present study we present a series of associations which might indicate causative mechanisms but do not prove them; proof could only be inferred from a longitudinal study of infant lung function where infant weight gain was modified in a randomised controlled manner.

\section{Conclusions}

In summary, this study reports two novel findings: (1) the change in V'maxFRC between 1 and 12 months of age was negatively related to weight gain over that period; and (2) infants with reduced change in $V^{\prime}$ maxFRC between 1 and 12 months of age, in association with reduced V'max FRC at 1 month of age, have increased early transient asthma symptoms and reduced $\mathrm{FEF}_{25-75}$ at 11 years of age. The relationships described are complex, but these observations will help understand possible mechanisms and useful therapeutic interventions.

Acknowledgements: The authors thank the children and their parents who have participated in the present study over the last 16 years, and also recognise the invaluable contributions to this cohort study made by many colleagues.

Funding: Dr Turner was funded by a grant from the National Health and Medical Research Council of Australia.

Competing interests: None.

\section{REFERENCES}

1. Martinez FD, Wright AL, Taussig LM, et al. Asthma and wheezing in the first six years of life. The Group Health Medical Associates. N Engl J Med 1995;332:133-8.

2. Kuehni CE, Davis A, Brooke AM, et al. Are all wheezing disorders in very young (preschool) children increasing in prevalence? Lancet 2001;357:1821-5.

3. Rusconi F, Galassi C, Corbo GM, et al. Risk factors for early, persistent, and lateonset wheezing in young children. SIDRIA Collaborative Group. Am J Respir Crit Care Med 1999;160:1617-22.

4. Turner SW, Palmer LJ, Rye PJ, et al. The relationship between infant airway function, childhood airway responsiveness and asthma. Am J Respir Crit Care Med 2004;169:921-7.

5. Clarke JR, Salmon B, Silverman M. Bronchial responsiveness in the neonatal period as a risk factor for wheezing in infancy. Am J Respir Crit Care Med 1995;151:143440.

6. Palmer LJ, Rye PJ, Gibson NA, et al. Airway responsiveness in early infancy predicts asthma, lung function, and respiratory symptoms by school age. Am J Respir Crit Care Med 2001;163:37-42.

7. Young S, Sherrill DL, Arnott J, et al. Parental factors affecting respiratory function during the first year of life. Pediatr Pulmonol 2000;29:331-40.

8. Dezateux C, Stocks J, Dundas I, et al. Impaired airway function and wheezing in infancy: the influence of maternal smoking and a genetic predisposition to asthma. Am J Respir Crit Care Med 1999;159:403-10.

9. Tager IB, Weiss ST, Munoz A, et al. Longitudinal study of the effects of maternal smoking on pulmonary function in children. N Engl J Med 1983;309:699-703.

10. Hoo A-F, Stocks J, Lum S, et al. Development of lung function in early life influence of birth weight in infants of non-smokers. Am J Respir Crit Care Med 2004;170:527-33. 
11. Lucas JS, Inskip HM, Godfrey KM, et al. Small size at birth and greater post natal weight gain relationships to diminished infant lung function. Am J Respir Crit Care Med 2004;170:534-40.

12. Friedrich $\mathbf{L}$, Stein RT, Pitrez PM, et al. Reduced lung function in healthy preterm infants in the first months of life. Am J Respir Crit Care Med 2006;173:442-7.

13. Young S, Le Souëf PN, Geelhoed GC, et al. The influence of a family history of asthma and parental smoking on airway responsiveness in early infancy. N Engl J Med 1991;324:1168-73

14. Pepys J. Skin tests for immediate, type I, allergic reactions. Proc $R$ Soc Med 1972;65:271-2.

15. Gardner RM, Hankinson JL, Clausen JL, et al. Standardisation of spirometry: 1987 update. Am Rev Respir Dis 1987;136:1285-98.

16. Yan K, Salome C, Woolcock AJ. Rapid method for measurement of bronchial responsiveness. Thorax 1983;38:760-5.
17. Young S, Arnott J, O'Keeffe PT, et al. The association between early life lung function and wheezing during the first 2 yrs of life. Eur Respir $J$ 2000;15:151-7

18. Castro-Rodriguez JA, Holberg CJ, Wright AL, et al. Association of radiologically ascertained pneumonia before age 3 yr with asthmalike symptoms and pulmonary function during childhood: a prospective study. Am J Respir Crit Care Med 1999:159:1891-7.

19. Oddy WH, Sly PD, de Klerk NH, et al. Breast feeding and respiratory morbidity in infancy: a birth cohort study. Arch Dis Child 2003;88:224-8.

20. Oddy WH, Sherriff JL, de Klerk NH, et al. The relation of breastfeeding and body mass index to asthma and atopy in children: a prospective cohort study to age 6 years. Am J Public Health 2004;94:1531-7.

21. Friedman $\mathbf{N} \mathbf{J}$, Zeiger RS. The role of breast-feeding in the development of allergies and asthma. J Allergy Clin Immunol 2005;115:1238-48.

\section{Pulmonary puzzle}

\section{ANSWER}

From the question on page 193.

A CT-guided biopsy of the right lung tumour revealed adenocarcinoma with a positive stain of thyroid transcription factor-1. A complete staging investigation composed of CT scans of the head and the chest including the upper abdomen and a whole body bone scan revealed T2NOM0 stage IB disease. An episode of pre-core mutant hepatitis B flare developed. Lamivudine was initiated. Right upper lobe lobectomy was postponed for 3 months after the recovery of liver function. Unfortunately, postoperative pathology staging revealed T2N2M0 stage IIIA disease. The patient is currently receiving adjuvant chemotherapy.

Synchronous primary pulmonary MALToma and adenocarcinoma are extremely rare. There is only one case reported in the English literature. ${ }^{1}$ Primary pulmonary non-Hodgkin's lymphoma is rare and accounts for $3.6 \%$ of all extranodal lymphomas; of these, $69-78 \%$ are MALTomas. ${ }^{2}$ The aetiology of synchronous malignancies is unclear, with environmental and genetic factors playing a part. ${ }^{1}$ Patients with lymphomas have a higher risk of developing other cancers. ${ }^{3}$ However, most of the reported case series demonstrate the role of Helicobacter pylori in the development of gastric MALToma and second primary gastric cancers. ${ }^{3}$ In the scanty literature related to our case, an abnormality on chromosome 3 has been reported in MALToma ${ }^{4}$ and nonsmall cell lung cancers. ${ }^{5}$ Further study is needed to evaluate its implications.

According to the treatment course in our case, the unresolved residual lymphoma might explain the persistent right upper lung tumour after the six cycles of chemotherapy, but a timely diagnostic procedure should have been performed to elucidate the causes in differing treatment responses. Tissue biopsy, though invasive, is crucial in making a correct diagnosis, particularly when the result could be a curable disease entity. In such a scenario, pulmonary adenocarcinoma could have been diagnosed at stage IB. Moreover, the patient could have been prevented from suffering the rituximab-related pre-core mutant hepatitis B flare and the delay in curative treatment for lung cancer.

This case highlights the importance of critical thinking on synchronous pulmonary malignancies and a timely diagnostic procedure to clarify the ambiguous clinical situations, especially when treatment discloses differing responses.

Thorax 2008;63:239. doi:10.1136/thx.2007.08511a

\section{REFERENCES}

1. Chanel S, Burke L, Fiche M, et al. Synchronous pulmonary adenocarcinoma and extranodal marginal zone/low-grade B-cell lymphoma of MALT type. Hum Pathol 2001;32:129-32.

2. Fiche M, Capron F, Berger F, et al. Primary pulmonary non-Hodgkin's lymphomas. Histopathology 1995;26:529-7.

3. Montalban C, Castrillo JM, Lopez-Abente G, et al. Other cancers in patients with gastric MALT Iymphoma. Leuk Lymphoma 1999:33:161-8.

4. Wotherspoon AC, Finn TM, Isaacson PG. Trisomy 3 in low-grade B-cell lymphomas of mucosa-associated lymphoid tissue. Blood 1995;85:2000-4.

5. Sozzi G, Veronese ML, Negrini M, et al. The FHIT gene at 3p14.2 is abnormal in lung cancer. Cell 1996;85:17-26. 